
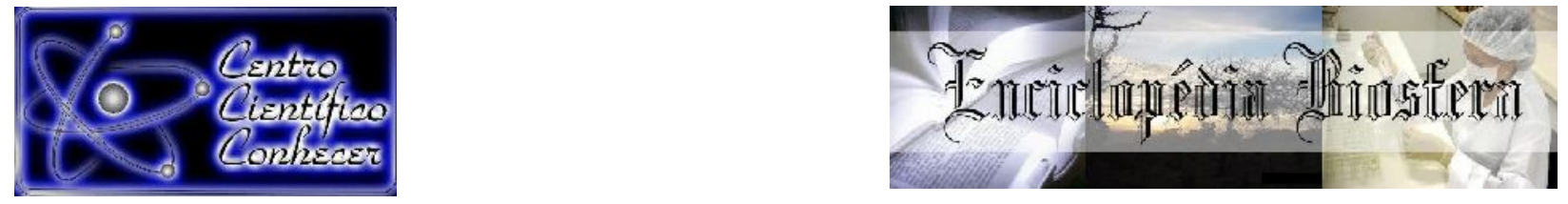

\title{
CONSTRUCCÃO DE MODELOS DIDÁTICOS NO ENSINO DE CIÊNCIAS: UMA FERRAMENTA PARA FACILITAR A APRENDIZAGEM DO SISTEMA URINÁRIO
}

Tiago Rodrigues da Silva ${ }^{1}$; Bruna Rodrigues da Silva ${ }^{2}$; Tamyres Lopes Rios ${ }^{2}$; Jackson Rafael do Nascimento França ${ }^{3}$

${ }^{1}$ Professor de Ciências da Rede Municipal de Ensino de Timon, MA, Brasil, thiago2581@hotmail.com

${ }^{2}$ Graduandas em Licenciatura em Ciências Biológicas pelo Instituto Federal do Piauí, campus Teresina Central, PI, Brasil.

${ }^{3}$ Graduado em Licenciatura em Ciências Biológicas pelo Instituto Federal do Maranhão, Campus Timon, MA, Brasil.

Recebido em: 22/09/2018 - Aprovado em: 23/11/2018 - Publicado em: 03/12/2018 DOI: 10.18677/EnciBio_2018B108

\begin{abstract}
O ensino de Anatomia Humana tradicionalmente é abordado com valorização apenas da transmissão e memorização das morfologias e fisiologias dos órgãos que compõem os sistemas orgânicos. Por isso, buscou-se viabilizar um método de ensino que coloque os alunos como sujeitos ativos de sua aprendizagem. Nesse sentido, o estudo objetivou analisar o desenvolvimento e aplicação da modelização didática na aprendizagem do sistema urinário. A experiência didática ocorreu em uma turma de 30 alunos no $8^{\circ}$ ano do ensino fundamental de uma escola pública localizada na cidade de Timon, MA. Os dados foram coletados por meio da aplicação de um pré-teste, observações dos pesquisadores e pós-teste. O pré-teste avaliou os conhecimentos após as aulas teóricas, e o pós-teste como os conteúdos foram compreendidos pelos alunos com a construção dos modelos didáticos. Observou-se no pós-teste que cerca de $90 \%$ os alunos responderam de forma satisfatória às questões relacionadas aos órgãos e funções do aparelho urinário. Assim, a atividade de modelização didática permitiu aos alunos uma compreensão integrada da morfologia e fisiologia do sistema urinário e estruturas internas dos rins. Os modelos didáticos, de baixo custo e fácil obtenção, construídos pelos estudantes se apresentaram como ferramentas eficazes para facilitar uma aprendizagem do aparelho urinário.
\end{abstract}

RESUMO

PALAVRAS-CHAVE: Anatomia, Modelização, Rins.

\section{CONSTRUCTION OF DIDACTIC MODELS IN SCIENCE TEACHING: A TOOL TO FACILITATE THE LEARNING OF THE URINARY SYSTEM}

\begin{abstract}
The teaching of Human Anatomy is traditionally approached with valuation only of the transmission and memorization of the morphologies and physiologies of the organs that make up the organic systems. Therefore, we tried to make feasible a teaching method that places the students as active subjects of their learning. In this sense, the study aimed to analyze the development and application of didactic modeling in the learning of the urinary system. The didactic experience occurred in a class of 30
\end{abstract}


students in the 8th year of elementary school of a public school located in the city of Timon, MA. The data were collected through the application of a pre-test, observations of the researchers and post-test. The pretest evaluated the knowledge after the theoretical classes and the post-test how the contents were understood by the students with the construction of didactic models. It was observed in the post-test that about $90 \%$ the students answered in a satisfactory way the questions related to the organs and functions of the urinary apparatus. Thus, the didactic modeling activity allowed the students an integrated understanding of the morphology and physiology of the urinary system and internal structures of the kidneys. The low-cost, easy-to-obtain didactic models constructed by the students were presented as effective tools to facilitate a learning of the urinary tract.

KEYWORDS: Anatomy, Modeling, Kidneys.

\section{INTRODUÇÃO}

A Anatomia (do grego: ana=através de; tomein=cortar) é a ciência que estuda micro e macroscopicamente, a constituição e o desenvolvimento dos seres vivos. Particularmente, a Anatomia Humana ocorre por meio da anatomia sistêmica, responsável pela compreensão macroscópica e analítica dos sistemas orgânicos corpóreos (DANGELO; FATTINI, 2011).

A Anatomia Humana trata-se de uma área do conhecimento que sempre exerceu curiosidades sobre os homens, posto que procura compreender as formas e funções de seus órgãos. Porém, o ensino e aprendizagem de Anatomia Humana na educação básica apresentam dificuldades, principalmente em razão da linguagem técnica complexa. Conforme, Krasilchik (2004) nas aulas de Anatomia Humana há uma ênfase na nomenclatura em lugar do destaque analítico das estruturas e processos biológicos. Assim, para a autora o excesso de vocabulário leva os alunos a entenderam que a aprendizagem de morfologia e fisiologia dos sistemas corpóreos se restringe a memorização dos nomes e funções dos órgãos.

$O$ ensino e aprendizagem de Anatomia Humana são considerados desafiadores, uma vez que seus conceitos não devem ser memorizados, mas compreendidos a partir das relações intrínsecas que acontecem entre a morfologia e fisiologia dos órgãos. Além disso, existe a necessidade de contextualizar os conceitos e funções dos sistemas corpóreos com os aspectos ambientais e culturais da sociedade na medida em que os hábitos alimentares e cotidianos se refletem na saúde dos sistemas orgânicos. Por conta disso, os Parâmetros Curriculares Nacionais (PCN) tratam o ensino do corpo humano como uma das formas de abordar e incentivar o ensino à saúde (BRASIL, 1997).

Paralelamente às situações destacadas, as abordagens metodológicas utilizadas pelos professores não contribuem para uma aprendizagem do corpo humano com vista para o ensino de saúde (BAPTISTA et al., 2015; MORAES; GUIZZETTI, 2016; VIANNAY; SELLES, 2016; RAMOS et al., 2018). De modo geral, a prática docente é centralizada apenas em aulas teóricas e expositivas com auxílio de livros didáticos que trazem imagens estáticas e fragmentadas do corpo humano. Nesse sentido, Macêdo et al. (2015) e Ramos et al. (2018) apontam que as aulas que buscam a memorização de termos e conceitos anatômicos e funcionais do corpo humano contribui de maneira significativa para a passividade dos alunos durante os processos de ensino e aprendizagem de Anatomia Humana.

Outro ponto importante é que o ensino ideal da Anatomia Humana deve ser realizado, principalmente, por peças cadavéricas humanas, previamente dissecadas 
para obter melhores percepções do formato, tamanho, profundidade e disposição dos órgãos que compõem os sistemas orgânicos (DANGELO; FATTINI, 2011). Contudo, as aquisições de peças anatômicas demandam altos custos financeiros e burocráticos, bem como princípios legais e éticos (MOURTHÉ FILHO et al., 2016).

Dado isso, as compreensões de Anatomia Humana vistas na educação básica são limitadas às descrições audiovisuais, uma vez que as escolas não dispõem de laboratórios equipados para aulas práticas dos sistemas corpóreos humanos. Nesse sentido, o professor deve contornar essas dificuldades com criatividade e executando atividades que requerem materiais, de baixo custo e fácil obtenção, e que podem tornar os conteúdos agradáveis e favoráveis à construção de conhecimentos pelos alunos.

Diante dos desafios apresentados ao ensino da disciplina de Anatomia Humana, os modelos didáticos ganham seu espaço nas aulas práticas, uma vez que permitem melhores visualizações dos órgãos quando comparados com a utilização apenas de livros didáticos (DUSSO et al., 2013; MOURTHÉ FILHO et al., 2016; ALEXANDRE et al., 2017; MACÊDO et al., 2017). Com isso, a modelização didática emergiu da necessidade de empregá-la para facilitar a aprendizagem dos alunos no ensino de Ciências (ASTOLFI; DEVELAY, 2012).

Dusso et al. (2013) aprofundam que os modelos pedagógicos são elaborados e aceitos como processos para uma aprendizagem no ensino de Ciências/Biologia e estão relacionados, principalmente, com as teorias da aprendizagem. Logo, o uso de modelos didáticos é um dos métodos alternativos para trabalhar o ensino de Anatomia Humana nas aulas de Ciências e Biologia (ALEXANDRE et al., 2017). Sendo, portanto, instrumentos pedagógicos capazes de explorar explicações dos processos biólogos por parte dos alunos, e que garantem a construção de conhecimentos (SETÚVAL; BEJARANO, 2009; ORLANDO et al., 2009).

Com efeito, os professores de Ciências/Biologia passaram a fazer usos de maquetes e esquemas com o objetivo de solidificar suas explicações sobre os conteúdos. Nesse sentido, torna-se mais propício estabelecer conexões e compreensões dos eventos naturais por parte dos estudantes (ORLANDO et al., 2009). Desse modo, Dusso et al. (2013) afirmam que os modelos didáticos usados no ensino de Biologia são representacionais de um sistema, objeto, fenômeno ou evento.

Diante do exposto, a ausência de um laboratório de Ciências para desenvolvimento de atividades práticas com peças cadavéricas foi um dos principais motivos para trabalhar com a modelização didática. Foi entendida também a necessidade de um ensino de Anatomia Humana que supere a redução do estudo de sistemas corpóreos guiados, principalmente, pelas ilustrações do livro didático, verbosidade do professor e passividade dos alunos durante as aulas.

Sendo assim, o presente estudo teve como objetivo analisar o desenvolvimento da modelização didática aplicada no ensino e aprendizagem do sistema urinário aos alunos no $8^{\circ}$ ano do Ensino Fundamental, em uma escola pública municipal de Timon, Maranhão.

\section{RELATO DE CASO}

O estudo foi de natureza básica com uma abordagem quali-quantitativa e descritiva quanto aos objetivos, caracterizando-se como uma pesquisa-ação (GIL, 2010). Assim, trata-se relato de caso que analisa uma estratégia metodológica para o ensino de Ciências/Biologia, propondo o uso de modelos didáticos. Desta forma, o presente estudo enquadra-se na perspectiva qualitativa da pesquisa sobre a própria 
prática docente (PALIS, 2009). Assim, essa abordagem ocorreu em razão de um dos autores ser, ao mesmo tempo, professor e pesquisador do contexto analisado.

A sequência didática foi realizada nos meses de agosto e início de setembro de 2018 com uma turma de 30 alunos do $8^{\circ}$ ano do Ensino Fundamental de uma escola pública, a Unidade Escolar Luiz Miguel Budaruiche, localizada na cidade de Timon, MA. A prática pedagógica foi aplicada em três etapas. A primeira com 04 aulas duplas semanais de 50 minutos (nos dias 01 e 08 de agosto) sobre os aspectos teóricos da morfologia e fisiologia do sistema urinário, leituras de textos acerca da saúde do sistema corpóreo supracitado e resolução de exercícios no quadro branco com apoio do livro didático dos alunos. Na segunda etapa (14 dias após a primeira) ocorreu um diagnóstico por meio do pré-teste para verificar os conhecimentos dos estudantes sobre o sistema urinário com base nas aulas expositivas e dialogadas.

Em seguida, ainda na segunda etapa, foi realizada a atividade de modelização didática na sala de aula. A construção dos modelos ocorreu pelos próprios alunos organizados em grupos - de três a quatro integrantes - com materiais de baixo custo, fácil obtenção, manuseio e disponibilizados pelo professor. Assim, na modelização didática os estudantes usaram folhas de E.V.A (etil vinil acetato), cola de isopor ou branca, tesouras e uma base de papelão nas dimensões de uma folha A4 $(21,0 \times 29,7 \mathrm{~cm})$. Os 18 modelos didáticos (09 do sistema urinário e 09 dos rins) foram desenvolvidos com base nas referências didáticos para nível fundamental proposto pelos autores Passos e Sillos (2015).

No decorrer da confecção dos modelos, o professor realizou explicações sobre as funções e órgãos que compõem o sistema urinário e esclarecendo as eventuais dúvidas dos alunos. Além disso, ao final da produção dos modelos pelos grupos de alunos, o professor realizava um jogo de perguntas e respostas aos estudantes. Nesse caso, lançava uma pergunta referente aos conteúdos abordados nos modelos, e selecionava um aluno para proferir a resposta, podendo haver a intervenção dos demais integrantes do grupo.

$\mathrm{Na}$ terceira etapa (12 de setembro) ocorreu a aplicação do pós-teste com a finalidade de averiguar a assimilação dos conteúdos conceituais com a construção dos modelos pelos alunos. Ou seja, examinar se a modelização contribui para a aprendizagem do sistema urinário. Ambos os testes, aplicados na primeira e terceira etapa, possuíam 09 questões categorizadas em morfologia e fisiologia do sistema urinário, conforme descrito no Quadro 01.

QUADRO 01: Questões usadas no pré-teste e pós-teste

\begin{tabular}{|l|l|}
\hline Categorias & \multicolumn{1}{c|}{ Questões } \\
\hline \multirow{5}{*}{ Morfologia } & \begin{tabular}{l}
\multicolumn{1}{c|}{ 1. Como é formado sistema urinário nos seres humanos? } \\
( ) rins e vias urinárias \\
( ) rins e bexiga \\
( ) vias urinárias e ureter \\
2. Quais são as vias urinárias? \\
( ) ureter, bexiga e uretra \\
( ) bexiga, uretra e rins \\
( ) ureter, pelve renal e uretra \\
3. Quais são as partes estruturais dos rins? \\
( ) córtex, medula renal e pelve renal \\
( ) córtex, medula renal e néfrons
\end{tabular} \\
\hline
\end{tabular}




\begin{tabular}{|l|l|}
\hline & $\begin{array}{l}\text { ( ) pelve renal, néfrons e medula } \\
\text { 4. Onde os néfrons estão localizados nos rins? } \\
\text { ( ) córtex ( ) pelve renal ( ) medula renal }\end{array}$ \\
\hline & 5. Qual a função do sistema excretor? \\
( ) produzir energia ( ) produzir ureia ( ) eliminar as excretas \\
6. Qual a função dos rins? \\
( ) reabsorção e filtração do sangue, produzindo a urina \\
( ) trocas gasosas \\
( ) controle da circulação sanguínea \\
7. Qual a função dos ureteres? \\
( ) conduzir a urina dos rins para a bexiga urinária \\
( ) formação da urina \\
( ) filtração do sangue \\
8. Qual a função da bexiga urinária? \\
( ) conduzir a urina dos rins para o ureter \\
( ) transportar a urina para o exterior do corpo \\
( ) receber e acumular a urina \\
9. Qual a função da uretra? \\
( ) coletar a urina do córtex \\
( ) reabsorção do sangue \\
( ) transportar a urina para o exterior do corpo
\end{tabular}

Fonte: Autores, 2018.

O desempenho dos alunos em ambos os testes foi comparado e serviu de parâmetros para analisar os resultados da proposta metodológica na aprendizagem dos estudantes. As respostas dos alunos, individualmente, foram comparadas e categorizadas para análises quali-quantitativa em certas e erradas. Desta forma, as observações verificadas pelo professor em sala aula, e os testes antes e após a modelização didática foram as técnicas utilizadas para coletar os dados e fazer a composição e triangulação dos resultados.

\section{RESULTADOS E DISCUSSÃO}

De início, foi perceptível a atenção e euforia por parte dos estudantes para construir os modelos didáticos. Também se verificou interações entre os alunos e um empenho em desenhar e recortar os moldes dos órgãos que compõem o sistema urinário, bem como das estruturas orgânicas que formam os rins. Nesse ponto, verificou-se uma socialização dos conhecimentos entre os estudantes na medida em que se identificaram diálogos acerca do formato, tamanho e localização dos rins e vias urinárias.

Com isso, tornou-se possível o professor notar a assimilação de alguns termos e significados que foram expressos nas aulas teóricas e dialogadas. Tais observações corroboram com resultados de Silva Filha et al. (2016) e Mâcedo et al. (2017) ao afirmarem que atividades de modelização são capazes de avivar o interesse dos alunos pelos conteúdos conceituais, promovendo o desenvolvimento da imaginação, reflexão e raciocínio. Adicionalmente durante a produção dos modelos didáticos, têm-se a oportunidade de o professor estabelecer maiores vínculos entre as aulas teóricas e a prática pedagógica de modelização, tornando o aluno um sujeito ativo e interativo nos processos de aprendizagem (SETÚVAL; BEJARANO, 2009; DUSSO et al., 2013; SILVA et al., 2017). 
A produção dos modelos didáticos incentivou os alunos a uma reflexão e pesquisas no livro didático sobre a morfologia e fisiologia do sistema urinário. $\mathrm{Na}$ realização da modelização didática foram confeccionados 18 modelos, 09 representando o sistema urinário e os demais modelos pedagógicos da morfologia dos rins. Na Figura 1 é possível observar alguns exemplos dos trabalhos de modelagem didática feitos pelos alunos.
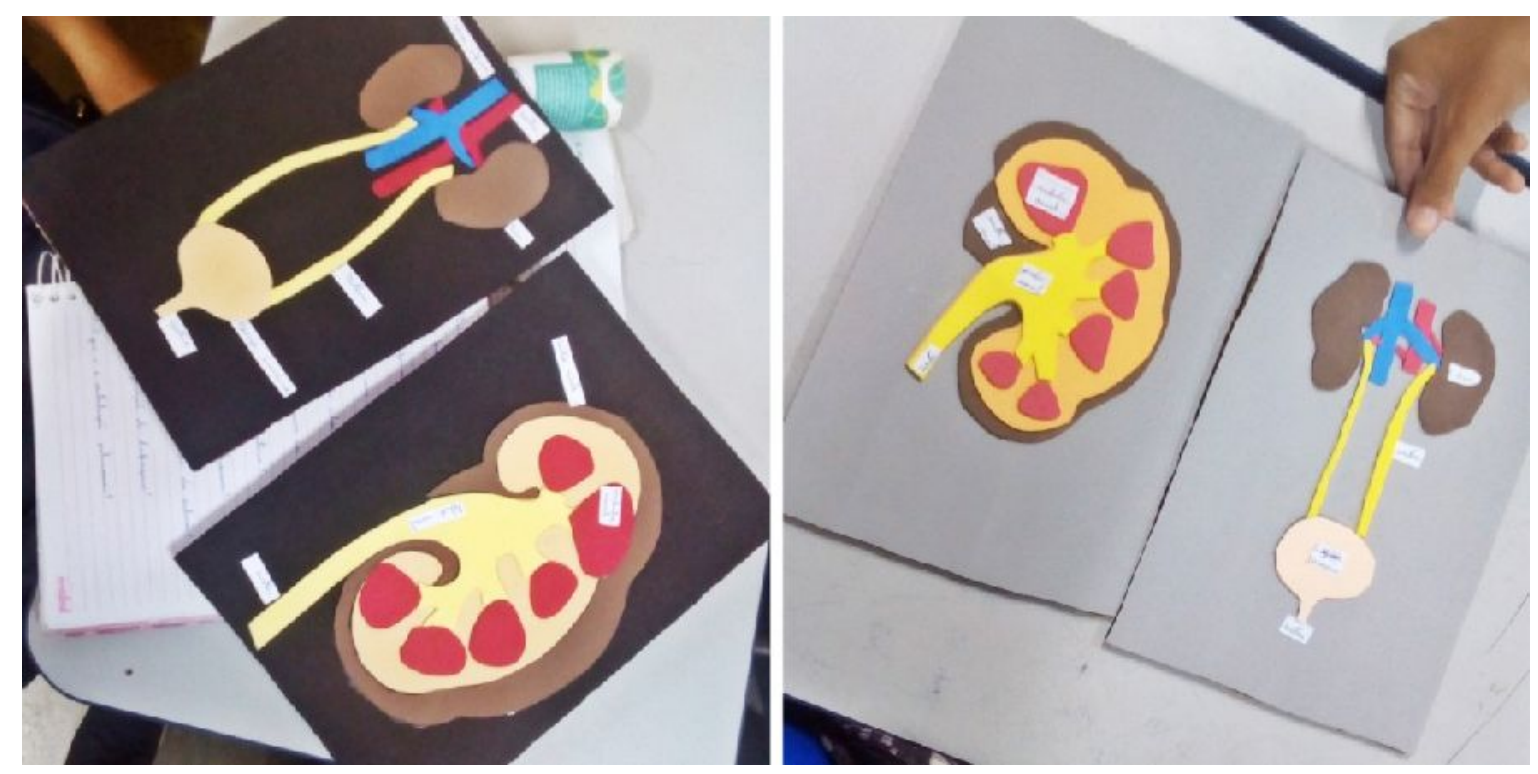

FIGURA 1: Modelos didáticos do sistema urinário e rins, construídos pelos alunos. Fonte: Autores, 2018.

Pode-se observar que os estudantes na construção de seus modelos foram desenvolvendo uma melhor capacidade de estabelecer as relações entre os órgãos do sistema corpóreo supracitado e seus posicionamentos anatômicos. Além disso, a atividade de modelização didática tornou-se um momento de aliar a construção de conhecimentos em Biologia com a produção artística dos alunos. Tendo isso em vista, Krasilchik (2004) afirma que os modelos didáticos não podem ser aplicados, puramente, como uma ilustração da teoria vista em sala de aula. Por isso, a autora advoga que os alunos sejam participativos nos processos que colocam a modelização didática para facilitar a aprendizagem.

Ao considerar a modelização didática como atividade prática, a construção dos modelos didáticos provocou uma experimentação física por parte dos alunos para que os estudantes desenvolvam uma capacidade de abstrair informações do objeto ou fenômeno abordado, por meio de confirmações dos conhecimentos apresentados nas aulas expositivas ou pela aquisição de novas informações que a experiência propicia (PAGEL et al., 2015). Desta forma, as confecções dos modelos pelos alunos efetuam um aprimoramento dos conhecimentos abordados nas aulas teóricas, bem como permitiu aos estudantes construir seus conceitos e significados acerca dos sistemas do corpo humano, ao invés de receberem as informações de forma passiva (ORLANDO et al., 2009; ALEXANDRE et al., 2017; SILVA et al., 2017).

Diversos autores, tais como Setúval e Bejarano (2009), Orlando et al. (2009), Dusso et al. (2013), Silva Filha et al. (2016), Alexandre et al. (2017), Silva et al. (2017) e Mâcedo et al. (2017) quando abordam o uso de modelos didáticos na 
aprendizagem argumentam que os mesmos provocam melhorias na fixação dos conteúdos científicos nas estruturas cognitivas dos alunos, pois ocorre o aumento da propensão dos estudantes relacionarem o material produzido com as funções biológicas e órgãos que estão sendo representados.

De fato, isso é percebido nos resultados do pós-teste das questões sobre morfologia, uma vez que houve uma melhoria na compreensão dos assuntos abordados após a atividade de modelização didática, conforme dados apresentados na Figura 2.

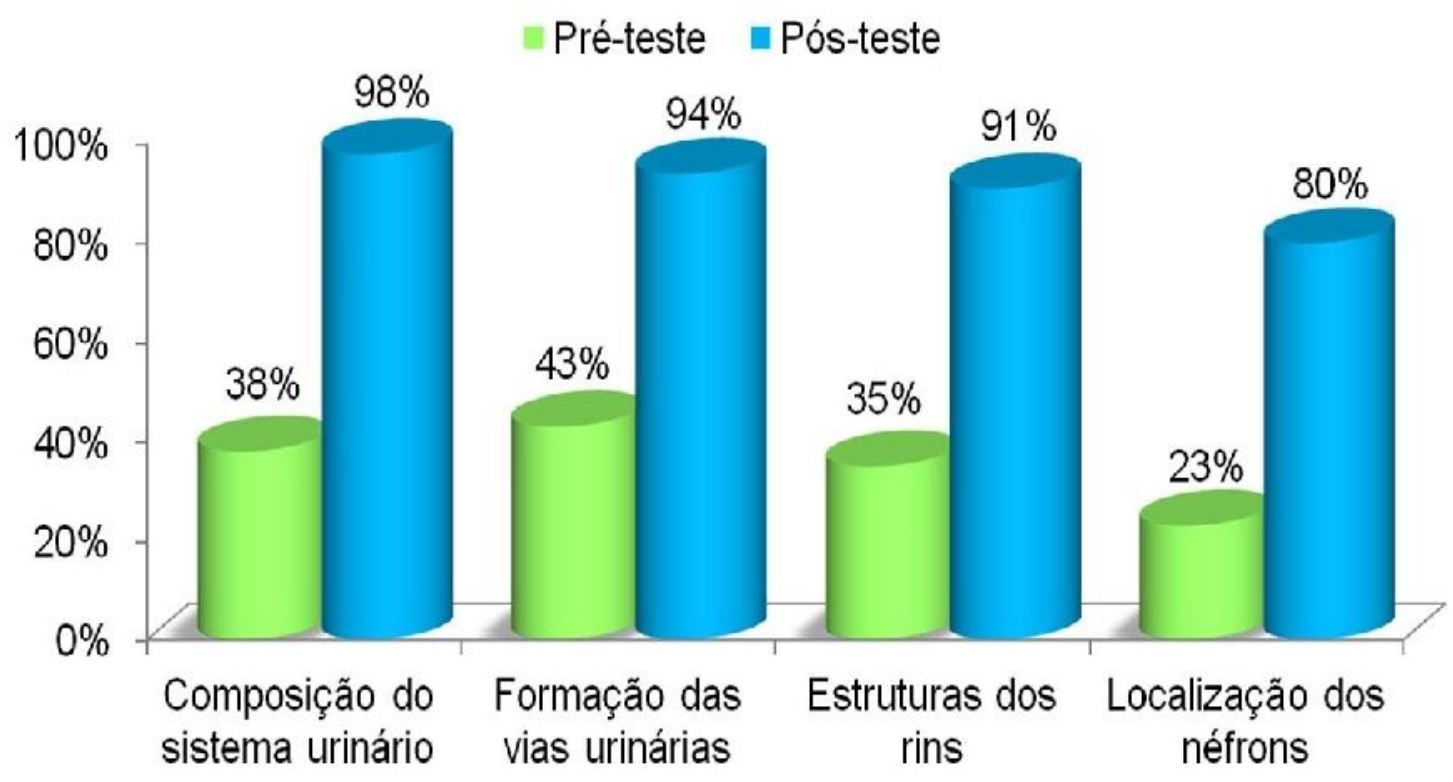

FIGURA 2: Porcentagem das respostas corretas das questões sobre morfologia do sistema urinário no pré-teste e pós-teste.

Fonte: Autores, 2018.

Como se pode constatar no pré-teste os alunos tiverem um desempenho inferior em comparação com a atividade de construção dos modelos didáticos. As respostas corretas na averiguação dos conhecimentos com base nas aulas expositivas não atingiram os patamares de $50 \%$ dos alunos. Contudo, os resultados não invalidam as abordagens, essencialmente, teóricas na aprendizagem dos alunos, em consequência de serem importantes para a introdução e apresentação de conceitos novos (KRASILCHIK, 2004).

O que se nota é que as aulas que seguiram os moldes de uma abordagem tradicional de ensino não foram suficientes para promover significação dos conceitos acerca do sistema urinário nos alunos. Os dados expressados na Figura 2 mostram que no pré-teste os estudantes não possuíam facilidades em identificar e compreender os órgãos e estruturas que constituem o sistema corpóreo supracitado desde a sua visão mais geral até as unidades funcionais, os néfrons. À vista disso, o professor deve buscar o desenvolvimento de atividades que coloquem os alunos diante de experiências físicas através da manipulação de materiais concretos, as quais possam abstrair informações sobre os fenômenos biológicos estudados (PAGEL et al., 2015).

A modelização didática foi tomada como fundamental para retirar os alunos da passividade dos processos de ensino e aprendizagem. Assim, durante a 
elaboração de seus próprios modelos os estudantes estavam mais envolvidos na busca de informações, o que culmina em melhorias na aprendizagem, conforme os resultados do pós-teste apresentados na Figura 2. Compreende-se que a confecção dos modelos pelos alunos melhorou seus entendimentos sobre os rins e vias urinárias (ureteres, bexiga urinária e uretra) como as estruturas orgânicas que juntas formam o aparelho urinário.

Outro dado foi o aumento percentual de respostas corretas sobre as estruturas que compõem os rins. No pré-teste, somente 11 alunos (=35\%) apresentaram capacidade para reconhecer que o córtex, medula e pelve renal são as três regiões anatômicas que formam o órgão. Enquanto no pós-teste, houve o aumento para 27 estudantes $(=91 \%)$ com eficácia para identificar as estruturas internas que compõem os rins.

Por isso, a construção de modelos provoca nos alunos as possibilidades de uma aprendizagem por analogias a partir dos aspectos visuais resultantes da modelização didática (SETÚVAL; BEJARANO, 2009; ORLANDO et al., 2009). Nesse sentido, permite o desenvolvimento de um imaginário no cognitivo dos alunos sobre os sistemas naturais representados nos modelos didáticos (MÂCEDO et al. 2017).

Assim, a produção dos modelos expressou nos alunos as semelhanças da cor marrom na coloração natural dos rins, bem como no seu formato característico análogo ao feijão, o amarelo nos ureteres e tons rosa para a bexiga urinária (órgão de musculatura) e uretra (tubo muscular). Nos rins, a diferenciação das regiões corticais, camada externa em que estão localizados os milhões de néfrons, e medulares, camada central, na qual se veem nitidamente algumas pirâmides de Malpighi. O amarelo na pelve renal para expressá-la como extremidade superior da uretra na região interior dos rins e, tendo formado equivalente à de um funil. Além disso, as representações em vermelho da aorta e azul para a veia cava inferior.

Sobre a localização dos néfrons, no pré-teste a principal dificuldade observada nos alunos foram em abstraí-los como estruturas microscópicas localizadas no córtex renal e sendo as unidades filtradoras do sangue. Isso resultou nos índices de $23 \%$ (=07 alunos) de acertos no pré-teste. Apesar dos modelos não abordarem diretamente uma representação das estruturas microscópicas dos néfrons eles subentendem sua localização dentro dos rins. Tal aspecto reconhece que a utilização da modelização didática também foi eficaz para auxiliar os estudantes a percepção de estruturas e processos que ocorrem a nível microscópico.

Os modelos didáticos, desse modo, também permitem explicações em aspectos bidimensionais para as estruturas vistas nos livros didáticos (ORLANDO et al., 2009; SILVA et al., 2017). A modelização didática, portanto, torna os conteúdos científicos palpáveis para os alunos (ASTOLFI; DEVELAY, 2012; DUSSO et al., 2013).

Ainda sobre os conhecimentos do sistema excretor com a atividade de modelização didática, percebeu-se que também se efetuou um aumento na capacidade dos estudantes em entender a fisiologia do aparelho urinário. Ou seja, conforme dados da Figura 3 a construção dos modelos desenvolveu nos alunos a significação da formação da urina nos rins e a sua condução para o exterior do corpo por meio das vias urinárias. 


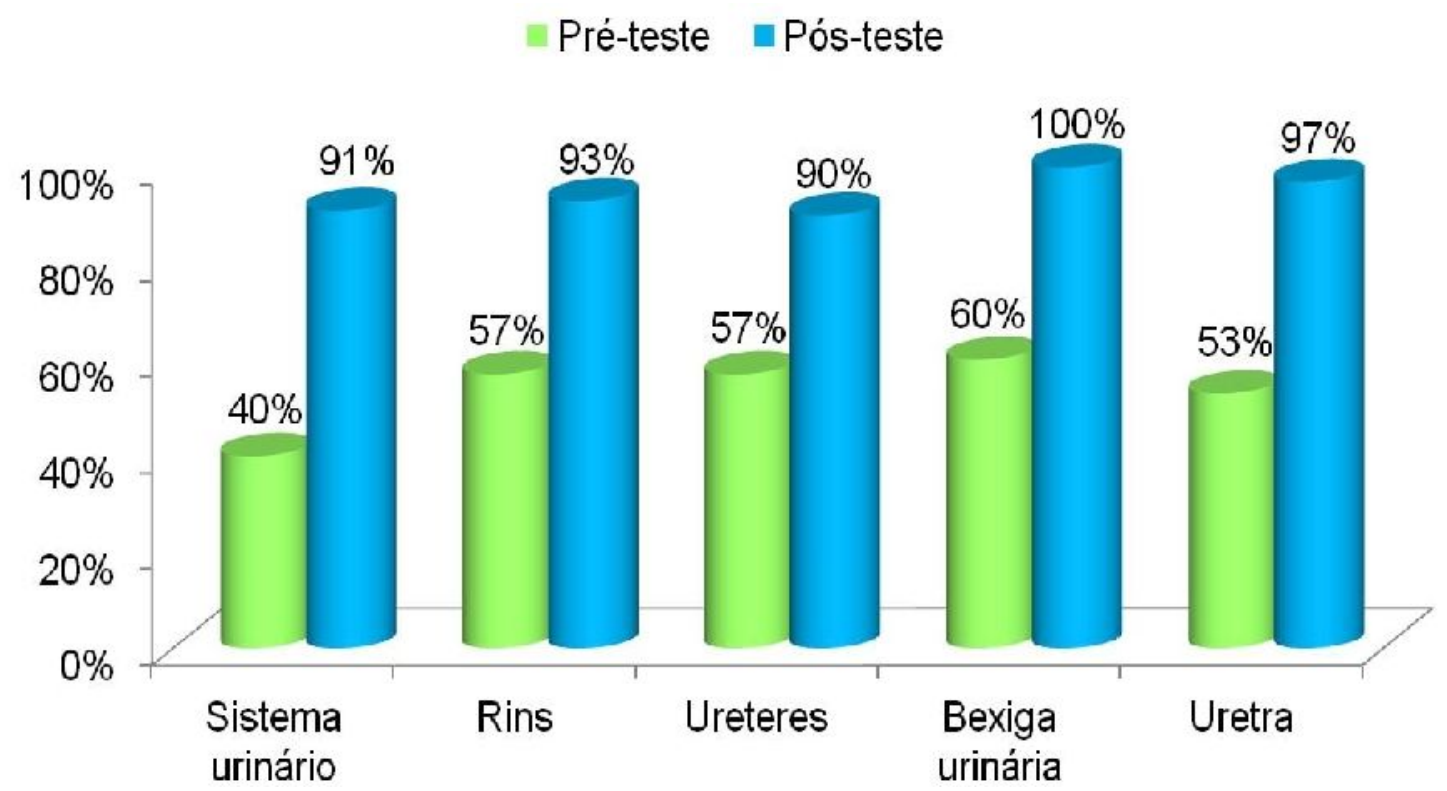

FIGURA 3: Porcentagem das respostas corretas das questões sobre fisiologia do aparelho urinário no pré-teste e pós-teste.

Fonte: Autores, 2018.

De modo geral, pode-se notar que os aspectos funcionais do sistema urinário também foram compreendidos pelos alunos na etapa do pós-teste nas questões sobre a função dos rins, ureteres, bexiga urinária e uretra, pois alcançaram índices de acertos superiores a $50 \%$ dos estudantes. Para Moraes e Guizzetti (2016) e Mourthé Filho et al. (2016) há indícios de melhorias nos processos de ensino e aprendizagem de Anatomia Humana quando os alunos apresentam capacidades de associar as nomenclaturas dos órgãos e estruturas com as respectivas funções.

Certamente, a atividade de modelização didática permitiu o aumento da aquisição de conhecimentos pelos alunos. Por exemplo, o índice de acertos na questão referente à função da bexiga urinária (acumular urina) atingiu $100 \%$ de alunos no pós-teste. Em relação à função dos rins a sua modelagem permite aos estudantes visualizarem as suas estruturas internas, por consequência esclarece 0 local de filtração e reabsorção do sangue, produção e coleta da urina para a pelve renal. Nesse ponto, os modelos didáticos da aorta e veia cava inferior presentes na modelagem do sistema urinário foram essenciais para o entendimento dos alunos, uma vez que expressam os vasos sanguíneos que conduzem o sangue à filtragem dos rins.

Contudo, os modelos didáticos dos rins apresentam a limitação de não possuírem os capilares sanguíneos na região do córtex. Mesmo assim, foram capazes de melhorar a compreensão dos alunos sobre a fisiologia do órgão como expressa os dados da Figura 3. Tem-se no pré-teste que somente 17 alunos $(=57 \%)$ acertaram a questão sobre a função dos rins, enquanto no pós-teste $28(=93 \%)$ obtiveram êxito.

Nesse sentido, os modelos didáticos são ferramentas capazes de compor um melhor entendimento da fisiologia dos órgãos, uma vez que o contato físico com a modelização permite uma visualização das estruturas, e por consequência torna os conceitos menos abstratos (RIBEIRO et al., 2016; SILVA et al., 2017). Assim, a utilização de modelos didáticos nas aulas reforçou os conteúdos de fisiologia vistos nas aulas teóricas e expositivas, ou seja, provocaram resignificações aos termos e 
conceitos apresentados nas aulas tradicionais. Desta forma, a modelização didática no ensino de Ciências permitiu promover uma transposição didática dos conteúdos científicos, facilitando uma aprendizagem (DUSSO et al., 2013; SILVA FILHA et al., 2016).

Ao observar os resultados do pré-teste acerca da morfologia e fisiologia do aparelho urinário torna-se possível afirmar que a atividade de modelização didática oportunizou aproximações dos conceitos científicos representados nos modelos didáticos com o próprio corpo dos discentes. Dessa forma, os estudantes puderam compreender que o sistema urinário faz parte de sua realidade, bem como identificálo como parte estruturante de seu corpo humano. Isso para Mâcedo et al. (2015) constrói uma imagem que a morfologia e fisiologia humana são reais, palpáveis e que cercam o cotidiano das pessoas. Assim como, distancia dos alunos a percepção que o corpo humano está presente somente nas figuras estáticas do livro didático (MORAES; GUIZZETTI, 2016; VIANNAY; SELLES, 2016; RAMOS, et al., 2018).

As utilizações de modelos didáticos nas aulas de Ciências permitem a visualização das estruturas e fenômenos biológicos, sobretudo, quando as escolas não dispõem de laboratórios de Ciências/Biologia (ORLANDO et al., 2009; ORLANDO et al., 2009; ALEXANDRE et al., 2017; MACÊDO et al., 2017). Diante disso, os modelos didáticos são instrumentos importantes na sala de aula, permitido uma manipulação, observação e análise dos conteúdos conceituais apresentados no livro didático (SILVA et al., 2017; MACÊDO et al., 2017).

Com efeito, a produção dos modelos didáticos estabelece nos alunos uma maior capacidade de integrar os aspectos anatômicos e funcionais do sistema corpóreo estudado. Além disso, a compreensão da morfologia e fisiologia é o primeiro passo para um melhor entendimento dos problemas relacionados à saúde e prevenção de doenças do sistema corpóreo como preconiza Brasil (1997). Por isso, Baptista et al. (2015), Mourthé Filho (2016), Viannay e Selles (2016) e Ramos et al. (2018) afirmam a importância de inserir os aspectos de saúde no ensino de Anatomia Humana, uma vez que isso está relacionado na formação crítica dos alunos.

\section{CONCLUSÃO}

Diante dos desafios do ensino de Ciências, tais como a falta de laboratórios, desânimo dos alunos e aulas puramente tradicionais que tornam os estudantes simples espectadores da verbalização dos conteúdos pelos professores, a utilização dos modelos didáticos mostrou-se uma saída viável para que os alunos despertassem interesses pelos conteúdos científicos, e se tornassem participativos e ativos na construção de seus conhecimentos. Sendo o professor, nesse momento, um mero mediador da aprendizagem dos alunos.

Os resultados obtidos mostraram que a atividade de modelização didática teve uma boa aceitação pelos alunos, permitindo-os revisar os conteúdos ministrados nas aulas teóricas e expositivas de forma palpável. Além disso, a construção dos modelos didáticos mostrou ser uma atividade que permite colocar os alunos em processos de socialização de conhecimentos.

Com a atividade de modelização didática foi possível verificar evoluções em identificar e compreender a morfologia e fisiologia dos órgãos do sistema urinário. Desse modo, torna-se viável concluir que após a construção dos modelos didáticos se obteve melhores concepções dos conteúdos científicos vistos durante as aulas semanais de Ciências. Além disso, também desenvolveu nos alunos uma 
capacidade de identificação do aparelho urinário como parte constituinte e essencial de seu corpo.

Portanto, entende-se aqui que a construção dos modelos didáticos pelos alunos não se configurou como uma atividade mecânica de desenho, mediação e observação, uma vez que houve participações ativas dos estudantes nos processos de ensino e aprendizagem. Isso significa dizer que, os discentes fizeram uso de análises, interpretações e reflexões sobre a morfologia e fisiologia do sistema urinário durante a atividade de modelização didática.

\section{REFERÊNCIAS}

ALEXANDRE, J. S.; MENDONÇA, V. A.; MENDONÇA, M. C. F. B. Construção de modelos didáticos para o ensino de ciências: sistema urinário. Experiências no Ensino de Ciências, v, 12, n. 7, p. 100-107, 2017. Disponível em: <http://if.ufmt.br/eenci/artigos/Artigo_ID425/v12_n7_a2017.pdf>.

ASSUNÇÃO, M. P. B.; CARNEIRO, L. G.; VIGÁRIO, A. F. O conhecimento anatômico ao alcance dos alunos de ensino médio de escola pública em Catalão Goiás a partir de aulas problematizadoras. Enciclopédia Biosfera, Goiânia, v. 15, n. 27, p. 231-243, 2018. Disponível em: <http://www.conhecer.org.br/enciclop/2018a/human/o\%20conhecimento\%20anatomi co.pdf >. Doi: 10.18677/EnciBio_2018A109.

ASTOLFI, J. P.; DEVELAY, M. A didática das ciências. Magda Sento Sé Fonseca [tradução]. 16 ed. Campinas/SP: Papirus, 2012.

BAPTISTA, V. I. A.; LIMA, J. M.; MEDEIROS, K. M. A.; SCARDUA, A.; BAPTISTA, J. S. Concepções sobre anatomia humana de alunos do ensino médio da cidade de Cuité-PB: funções e relações com cotidiano. Revista Brasileira de Pesquisa em Educação em Ciências, v. 25, n. 1, p. 59-78, 2015. Disponível em:<https://seer.ufmg.br/index.php/rbpec/article/view/2506>.

BRASIL, Parâmetros Curriculares Nacionais: Saúde. Brasília: Ministério da Educação, 1997.

DANGELO, J. G.; FATTINI, C. A. Anatomia humana sistêmica e segmentar. 3. ed. São Paulo: Editora Atheneu, 2011.

DUSSO, L; CLEMENT, L; PEREIRA, P. B.; ALVES FILHO, J. P. Modelização: uma possibilidade didática no ensino de biologia. Revista Ensaio, Belo Horizonte, v. 15, n. 2, maio-ago., p. 29-44, 2013. Disponível em: <https://seer.ufmg.br/index.php/ensaio/article/view/8396/6333>.

GIL, A. C. Como elaborar projetos de pesquisa. 5. ed. São Paulo: Altas, 2010.

KRASILCHIK, M. Práticas no ensino de biologia. 4. ed. São Paulo: EDUSP, 2008.

MACÊDO, E. G.; MACÊDO, F. C. S.; CAVALCANTI, A. S. Conceitos de imagem do corpo humano para os conteúdos de ciências. Revista Científica Mathephys, v. 1, n. 1, jan./jun., p. 21-20. 2015. Disponível em: <https://www5.ifpi.edu.br/revistas/index.php/mathephys/article/view/14/88>. 
MACÊDO, F. C. S.; SILVA, T. R.; MÂCEDO, E. G. Intervenção pedagógica pela pesquisa como estratégia de estágio para o ensino e aprendizagem do sistema cardiovascular. Revista Prática Docente, Confresa, MT. v. 2, n. 2, jul./dez., p. 270291, $2017 . \quad$ Disponível em: <http://periodicos.cfs. ifmt.edu.br/periodicos/index.php/rpd/article/view/82/39>. Doi: 10.23926/RPD.2526-2149.2017.v2.n2.p270-291.id82.

MORAES, V. R. A.; GUIZZETTI, R. A. Percepções de alunos do terceiro ano do ensino médio sobre o corpo humano. Ciência \& Educação, Bauru, v. 22, n. 1, p. 253-279, 2016. Disponível em: <http://www.scielo.br/pdf/ciedu/v22n1/1516-7313ciedu-22-01-0253.pdf>. Doi: 10.1590/1516-731320160010016.

MOURTHÉ FILHO, A,; BORGES, M. A. S; FIGUEIREDO, I. P. R.; VILLALOBOS, M. I. O.; TAITSON, P. F. Refletindo o ensino da anatomia humana. Enfermagem Revista, Belo Horizonte, v. 19, n. 2, p. 169-175, 2016. Disponível em: <http://periodicos.pucminas.br/index.php/enfermagemrevista/article/view/13146/102>

ORLANDO, T. C.; LIMA, A. R.; SILVA, A. M.; FUZISSAKI, C. N.; RAMOS, C. L; MACHADO, D.; et al. Planejamento, montagem e aplicação de modelos didáticos para uma abordagem de biologia celular e molecular no ensino médio por graduandos de ciências biológicas. Revista Brasileira de Ensino de Bioquímica e Biologia Molecular, n. 1, 2009. Disponível em: <http://bioquimica.org.br/revista/ojs/index.php/REB/article/view/33/29>. D Doi: 10.16923/reb.v7i1.33

PAGEL, U. R.; CAMPOS, L. M.; BATITUCCI, M. C. P. Metodologias e práticas docentes: uma reflexão acerca da contribuição das aulas práticas no processo de ensino e aprendizagem de biologia. Experiências em Ensino de Ciências, v. 10, n. 2, $\quad$ p. $14-25, \quad 2015.2$ Disponível em: <http://if.ufmt.br/eenci/artigos/Artigo_ID273/v10_n2_a2015.pdf>.

PALIS, G. L. Pesquisa sobre a própria prática no ensino superior de matemática. In: FROTA, M. C. R.; NASSER, L. (Org.) Educação Matemática no Ensino Superior: pesquisas e debates. Recife: SBEM, p. $203-221,2009$.

PASSOS, E; SILLOS, A. Tempo de Ciências 8. 2. ed. São Paulo: Editora do Brasil, 2015.

RAMOS, K. C. A. B.; FONSECA, L. C. S.; GALIETA, T. Visões sobre o ser humano e as práticas docentes no ensino de ciências e biologia. Revista Exitus, Santarém/PA, v. 8, n. 1, jan./abr., p. 305-331, 2018. Disponível em: <https://www.researchgate.net/publication/321782285>. Doi: 10.24065/22379460.2018v8n1ID399.

RIBEIRO, A. S.; CARDOSO, A. P; PEREIRA, J. M. P.; SILVEIRA, M. G; SILVA, S. M.; MARIANO, T. F. S. O ensino de anatomia humana no $8^{\circ}$ ano do ensino fundamental associado a aulas práticas mediado por ações extensionistas. In: Congresso de ensino, pesquisa e extensão da UEG, 3, 2016, Pirenópolis, GO. 
Anais...Pirenópolis,

$\mathrm{GO}$,

UEG,

2016.

Disponível

em:<http://www.anais.ueg.br/index.php/cepe/article/view/8294/5743>.

SETÚVAL, F. A. R.; BEJARANO, N. R. R. Os modelos didáticos com conteúdos de genética e sua importância na formação inicial de professores para o ensino de ciência e biologia. In: ENCONTRO NACIONAL DE PESQUISA EM ENSINO DE CIÊNCIAS, 7. 2009. Anais...Florianópolis: ABECS, 2009. Disponível em: $<$ http://posgrad.fae.ufmg.br/posgrad/viienpec/pdfs/1751.pdf>.

SILVA FILHA, R. T.; SILVA, A. A.; FREITAA, S. R. S. Uma alternativa didática às aulas tradicionais de ciência: aprendizagem colaborativa e modelização aplicadas ao ensino do sistema urinário. Cadernos de Educação, v. 15, n. 31, jul./dez., p. 87105, 2016. Disponível em: <https://www.metodista.br/revistas/revistasims/index.php/cadernosdeeducacao/article/view/7071>. Doi: 10.15603/16798104/ce.v15n31p87-105.

SILVA, G. B.; RODRIGUES, A. B.; FREITAS, S. R. S. O ensino do tecido hematopoiético pela ótica da modelização: uma abordagem factível. Cadernos de Educação, v. 16, n. 32, jan./jun., p. 123-134, 2017. Disponível em: <https://www.metodista.br/revistas/revistasims/index.php/cadernosdeeducacao/articl e/view/7576>. Doi: 10.15603/1679-8104/ce.v16n32p123-134.

VIANNAY, C. V. C.; SELLES, S. L. E.; Produção acadêmica sobre o ensino do corpo humano nas disciplinas escolares ciências e biologia. Revista da Sociedade Brasileira do Ensino de Biologia, v. 9, p. 3897-3907, 2016. Disponível em: <http://www.sbenbio.org.br/wordpress/wp-content/uploads/renbio-9/pdfs/2136.pdf>. 